bone injury. Most cardiac abnormalities after crushing injury occur from blunt trauma after road traffic accidents, where deceleration causes damage to the anterior right ventricle. Electrocardiograms and cardiac enzyme activity are not sensitive indicators of this injury, but radionuclide scanning or echocardiography show abnormalities of right ventricular function..$^{1-3}$ Our patients had acute strain of the right heart because of severe pressure overload which occurs in asphyxiation or with a major pulmonary embolus. One patient only was haemodynamically compromised and required inotropic support.

Acute right heart strain may have occurred for several reasons. External compression, especially of the abdomen, causes increased filling of the right heart . Thoracic compression produces a rise in intrathoracic pressure and pulmonary artery pressure, which would rise further from an increase in pulmonary vascular resistance secondary to hypoxia. The possibility of a pulmonary fat embolus from a crushing injury could not be excluded. ${ }^{4}$ Finally, direct cardiac trauma and contusion of the septum and right ventricle was a possibility, supported by pericardial effusions in two patients and transient conduction abnormalities in two. ${ }^{1.3}$ The electrocardiographic and echocardiographic appearances improved in all six patients, and possibly no long term cardiac damage occurred. We did not test cardiac function, however, and the abnormal right ventricular function may interfere with exercise and normal activity in these young men.

We thank the following anaesthetists for their suppor of these patients: Drs S P Gerrish, P A Wilkinson, T Kirkpatrick, S Gill, A Magides, J McKay, and J Kennedy. We also thank the technical staff of the department of cardiology and the department of medical illustration for their help in preparing this report.

1 Rothstein RJ. Myocardial contusion. FAMA 1983;250:2189-91.

2 Rosenbaum RC, Johnston GS. Post-traumatic cardiac dysfunction: assessment with radionuclide ventriculography. Radiology 1986;160:91-4.

3 Harley DP, Mena I, Narahara KA, Miranda R, Nelson RJ. Traumatic myocardial dysfunction. $\mathcal{F}$ Thorac Cardiovasc Surg 1984;87:386-93.

4 Dehand FH, Bennett WA. Death due to bone marrow and tumor embolisation in the absence of fracture. Archives of Pathology 1957;63:13-6.

(Accepted 23 August 1989)

\title{
Fine bore silicone catheters for peripheral intravenous nutrition in adults
}

\section{Stanley R Kohlhardt, Ross C Smith}

\section{University of Sydney \\ Department of Surgery, Royal North Shore Hospital, St Leonards, New South Wales, Australia 2065 \\ Stanley R Kohlhardt, MB, research fellow Ross C Smith, MD, senior lecturer in surgery}

Correspondence to: $\mathrm{Dr}$ Kohlhardt. Reprint requests to: Dr Smith.

BrMed f 1989;299: 1380-1
The finest silicone central vein infusion catheter, intended for neonates, has been shortened and adapted for peripheral vein infusion in adults. We hypothesised that this catheter, used with a lipid based nutrition solution suitable for infusion via a peripheral vein, most closely approached the requirements for preventing infusion thrombophlebitis. These include using a short, soft, and flexible fine bore biocompatible catheter; sterile insertion technique; and an infusion solution with an osmolality up to $1000 \mathrm{mmol} / \mathrm{l}$ and $\mathrm{pH}$ greater than $5 \cdot 0 .{ }^{1}$ We therefore studied the complication rate when using this very fine catheter for peripheral intravenous nutrition.

\section{Methods and results}

Consecutive surgical inpatients requiring intravenous nutrition were studied. A fine bore silicone catheter (inside diameter $0.3 \mathrm{~mm}$, outside diameter $0.6 \mathrm{~mm}$, Vygon, Nutricath-S Epicutaneo-cave catheter) was inserted $15 \mathrm{~cm}$ into a median cubital vein. A transparent occlusive dressing secured the catheter, allowing unrestricted arm movement and observation of the puncture site. The catheters were used only for delivering intravenous nutrition.

The nutrition solutions were aseptically prepared in the pharmacy in 3 litre bags with about 100:1 energy (kcal) to nitrogen (g) $(0.42 \mathrm{MJ}: 1 \mathrm{~g}$ nitrogen) and $70 \%$ of non-protein energy supplied as lipid. Vitamins, trace elements, and sodium heparin $(1 \mathrm{unit} / \mathrm{ml})$ were added routinely and ranitidine $(200 \mathrm{mg} / 24 \mathrm{~h})$ when indicated. Mean osmolality was 1084 (SD 6.6) $\mathrm{mmol} / \mathrm{l}$ and $\mathrm{pH} 5.6$ $(0 \cdot 3)$. Patients received more than $35 \mathrm{kcal} / \mathrm{kg} /$ day $(0 \cdot 15$ $\mathrm{MJ} / \mathrm{kg} /$ day) and $0.35 \mathrm{~g}$ nitrogen $/ \mathrm{kg} /$ day using volumetric infusion pumps. Thrombophlebitis (judged by a single observer) was indicated by at least two of the following: erythema, pain, swelling, and tenderness. Phlebitis restricted to the catheter tip indicated chemical phlebitis, and two of the following indicated bacterial phlebitis: fever, heat, increased neutrophil count, and induration with a positive culture from the catheter tip or protracted resolution of inflammation. Bacteraemia was diagnosed by blood culture. Catheter tip culture was performed routinely.

Forty six patients aged 13-89 years received 61 catheters for 704 treatment days. Indications for intravenous nutrition included: gut rest after major surgery (32), pancreatitis (7), active Crohn's disease (3), and other reasons (4). The median duration of infusion was nine days (range 5-60). Thirty four patients required only one catheter, while seven required more than one, and five required a central catheter for some period. Forty one patients were treated with peripheral intravenous nutrition alone until enteral feeding was re-established. The figure shows the probability of continued catheter function. There were 11 episodes of phlebitis ( 10 chemical, one bacterial) with five recorded at completion of treatment. The median period to phlebitis was seven days (range 5-19). Two episodes were due to spontaneous retraction of the catheter with extravasation. Overall the daily risk of phlebitis was $0.016(11 / 704)$ with no instances of bacteraemia or septicaemia related to the catheter. One Staphylococcus epidermidis infection occurred at the insertion site without phlebitis and cleared without antibiotics. Subcutaneous extravasation of infusate occurred six times and fully resolved within 96 hours of the infusion being stopped at that site.

\section{Comment}

Conventional peripheral vein catheters used for nonirritant infusions are associated with an incidence of phlebitis of $30-100 \%$ after five days. ${ }^{2}$ Lipid based

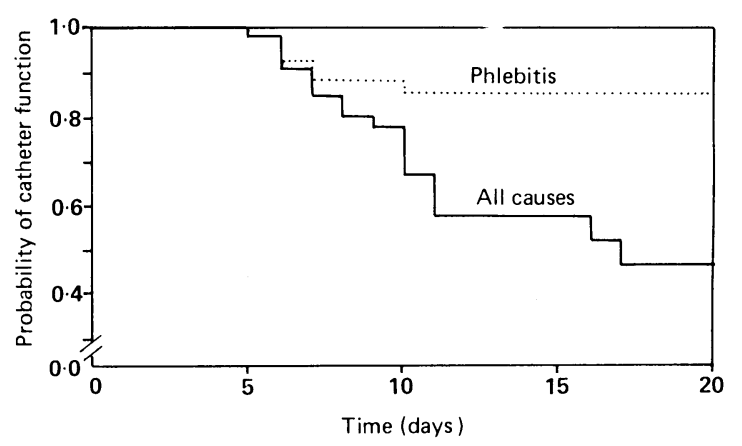

Probability that fine silicone catheters were functioning plotted against time in days as for life table analysis. Dotted line indicates probability of infusion thrombophlebitis 
intravenous nutrition solutions have been well tolerated when the osmolality is less than $983 \mathrm{mmol} / \mathrm{l}$ but the daily risk of extravasation is 0.54 for "butterfly" needles and of phlebitis 0.25 for short plastic catheters. ${ }^{3}$ The daily risk of phlebitis with our fine silicone catheters was $0 \cdot 016$, with a median period of function of nine days. One patient with pancreatic abscess received 60 days of complete intravenous nutrition through a single catheter. There were no bacteraemic episodes related to the catheter, while the expected rate with central intravenous nutrition is $4 \%$.

Intravenous nutrition solutions providing $70 \%$ of non-protein calories as lipid are efficacious, ${ }^{5}$ but their use has been limited because they are unsupported by an adequate delivery system. Their use with a fine silicone catheter may avoid the need for central vein cannulation in $89 \%$ of inpatients requiring intravenous nutrition.

1 Muller JM. Parenteral approaches in total parenteral nutrition therapy. Peripheral venous catheter versus central venous catheter. In: Educational programme of the 7th Congress of the European Society of Parenteral and Enteral Nutrition. Munich: ESPEN, 1985:193-218.

2 Lewis GBH, Hecker JF. Infusion thrombophlebitis. Br f Anaesth 1985;57: 2203.

Daly JM, Masser E, Hansen L, Canham JE. Peripheral vein infusion of dextrose/amino acid solutions $+20 \%$ fat emulsion. FPEN F Parenter Enteral Nutr 1985;9:296-9.

4 Nystrom B, Olesen Larsen S, Dankert J, et al. Bacteraemia in surgical patients with intravenous devices: a European multicentre incidence study. 7 Hosp Infect 1983;4:338-49.

5 Jeejeebhoy KN, Anderson GH, Nakhooda AF, Greenberg GR, Sanderson I, Marliss EB. Metabolic studies in total parenteral nutrition with lipid in man - comparison with glucose. $\mathcal{f}$ Clin Invest 1976;57:125-36.

(Accepted 30 August 1989)

\section{Pseudohyperphosphataemia in multiple myeloma}

\author{
E V McCloskey, J Galloway, M A Morgan, \\ J A Kanis
}

\section{Department of Human \\ Metabolism and Clinical \\ Biochemistry, University of \\ Sheffield Medical School, \\ Sheffield S10 2RX \\ E V McCloskey, MRCP, \\ medical research council \\ research fellow \\ J A Kanis, MD, clinical reader}

Department of Clinical

Chemistry, Royal

Hallamshire Hospital,

Sheffield S10 2JF

J Galloway, PHD, biochemist

\section{Department of}

Haematology,

Huddersfield Royal

Infirmary, Huddersfield

M A Morgan, MRCPATH, consultant

Correspondence to: $\mathrm{Dr}$ McCloskey.

Br.Med f 1989;299:1381-2 metabolism or renal function.

\section{Case report}

Abnormalities in serum inorganic phosphate concentrations are uncommon in multiple myeloma in the absence of renal impairment or hypoparathyroidism. We report a case of spurious hyperphosphataemia in a patient with no other abnormality of calcium

A 40 year old woman presented with a two month history of lethargy and dyspnoea on mild exertion after a viral infection had been diagnosed. She had appreciable anaemia (haemoglobin concentration $79 \mathrm{~g} / \mathrm{l}$ ) and an erythrocyte sedimentation rate $>140 \mathrm{~mm}$ in the first hour. Subsequent investigation showed an $\operatorname{IgG} \lambda$ myeloma. The serum concentration of inorganic phosphate, measured with a Hitachi 737 analyser, was $2.36 \mathrm{mmol} / 1$ (normal range $0.8-1.4 \mathrm{mmol} / \mathrm{l}$ ). There were no clinical manifestations of hyperphosphataemia. Serum calcium concentration (total $2.22 \mathrm{mmol} / \mathrm{l}$; $2.31 \mathrm{mmol} / \mathrm{l}$ when adjusted for serum albumin concentration), immunoreactive parathyroid hormone concentration $(62 \mathrm{pmol} / \mathrm{l}$ measured by mid-molecule radioimmunoassay), and renal function (urea concentration $4.4 \mathrm{mmol} / \mathrm{l}$; creatinine concentration $84 \mu \mathrm{mol} / \mathrm{l}$; creatinine clearance $95 \mathrm{ml} / \mathrm{min}$ ) were normal.

She was enrolled into the sixth Medical Research Council trial, in which she received doxorubicin, carmustine, cyclophosphamide, melphalan, and prednisolone and a placebo of clodronate. The chemotherapy induced a good response, and her serum IgG concentration fell from $72 \mathrm{~g} / \mathrm{l}$ to $33 \mathrm{~g} / \mathrm{l}$ within one month. The serum inorganic phosphate concentration decreased from 2.08 to $1.64 \mathrm{mmol} / \mathrm{l}$. Because of persistent bone marrow suppression all drugs apart from clodronate were stopped after five months and weekly cyclophosphamide was substituted; an increase in serum globulin concentration at this time was associated with an increase in serum phosphate concentration to $2.56 \mathrm{mmol} / 1$. A close correlation was observed between serum phosphate concentration and serum globulin $(\mathrm{r}=0.90)$ and serum total protein concentrations $(r=0.97)$ (figure).

Phosphate concentrations in six serum samples from the patient were subsequently assayed by three different techniques. Values obtained with an RA 1000 analyser showed persistent hyperphosphataemia $(2 \cdot 49$ - $2.73 \mathrm{mmol} / \mathrm{l}$; normal range for the technique 0.7 -
$1.5 \mathrm{mmol} / \mathrm{l})$; those obtained with a Technicon SMAC analyser $(1.46-1.53 \mathrm{mmol} / \mathrm{l})$ were at the upper end of the normal range $(0.7-1.5 \mathrm{mmol} / \mathrm{l})$; and those obtained by atomic emission spectroscopy $(1.92-2.01 \mathrm{mmol} / \mathrm{l})$ did not differ from those found in three normophosphataemic patients with myeloma and three normal subjects (range $1.62-2.40 \mathrm{mmol} / \mathrm{l}$ ).

\section{Comment}

Chronic hyperphosphataemia is rare and usually secondary to pronounced impairment of renal function. Other causes include hypoparathyroidism and pseudohypoparathyroidism and administration of drugs such as the diphosphonate etidronate. We were surprised, therefore, to observe appreciable hyperphosphataemia with normal creatinine clearance and normal serum concentrations of calcium and immunoreactive parathyroid hormone. Whereas etidronate increases serum phosphate concentrations, the effects of clodronate are small and transient.' In addition, hyperphosphataemia in this patient was present before treatment, so that clodronate is unlikely to have contributed to the high serum phosphate concentration.

The three methods for measuring inorganic phosphate in serum in our laboratories use chromogenic assays, ${ }^{2}$ but with the Technicon SMAC analyser many serum proteins and other macromolecules are removed before measurement. The lower serum concentrations of inorganic phosphate found with this method suggest either that the excess phosphate was bound to protein, possibly to an abnormal paraprotein, or that a paraprotein was interfering with the assay. The close correlation between serum phosphate and serum protein concentrations supports either possibility. Atomic emission spectroscopy measures the total inorganic and organic phosphate content of serum.

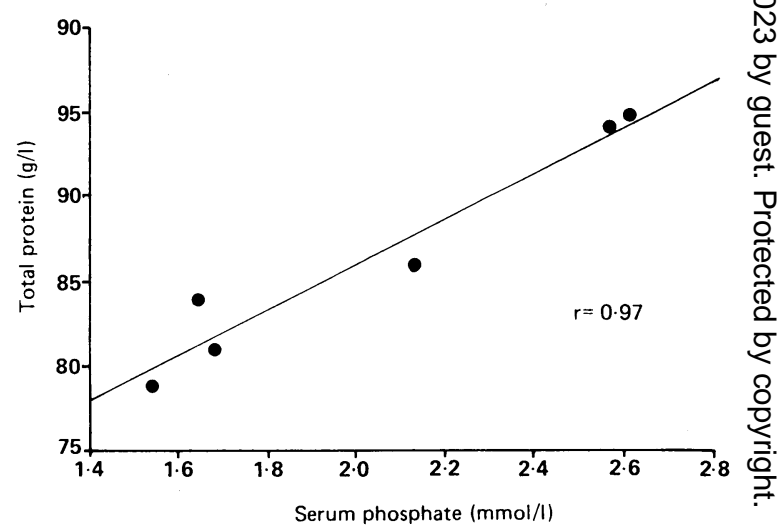

Correlation between apparent inorganic phosphate concentration in serum that had not been dialysed and serum total protein concentration in patient with multiple myeloma 